\title{
Comparative Pharmacognostical and Pharmacological Evaluation of Costus speciosus (Koen) J.E. Sm. Germplasm Collected from Eastern Ghats of India
}

\author{
Manish Kumar ${ }^{1,2}$, Ankita Misra', Akanksha Srivastava', Pushpendra Kumar Shukla', L. M. Tewari², Sharad \\ Srivastava ${ }^{1 * *}$
}

Manish Kumar ${ }^{1,2}$, Ankita

Misra', Akanksha Srivastava', Pushpendra Kumar Shukla', L. M. Tewari ${ }^{2}$, Sharad Srivastava ${ }^{1, *}$

'Pharmacognosy Division, CSIR-National Botanical Research Institute, Lucknow (U.P.) 226001, INDIA.

${ }^{2}$ Department of Botany, D.S.B. Campus, Kumaun University, Nainital-263002,

Uttarakhand, INDIA.

\section{Correspondence}

Dr. Sharad Srivastava

Senior Principal Scientist, Pharmacognosy division, CSIR-NBRI, Lucknow, INDIA.

Phone no: 91-522-2297818

Fax: 91-522-2205836

E-mail: sharad_ks2003@yahoo.com

History

- Submission Date: 03-10-2019;

- Review completed: 21-10-2019;

- Accepted Date: 04-11-2019.

DOI : 10.5530/pj.2020.12.22

Article Available online

http://www.phcogj.com/v12/i1

Copyright

(C) 2020 Phcogj.Com. This is an openaccess article distributed under the terms of the Creative Commons Attribution 4.0 International license.

\begin{abstract}
Background: Costus speciosus is an erect perennial herb belonging to family Costaceae, an important medicinal plant widely used in several indigenous medicinal formulations. Objective: A comparative evaluation of Pharmacognostical and Pharmacological potential of Costus speciosus for the validation of traditional claims and quality parameters for industry. Materials and Methods: Pharmacognostical studies were performed as per Ayurvedic Pharmacopeia of India and quantification of diosgenin was done through HPTLC. In vitro antidiabetic activity was evaluated by $\alpha$-amylase inhibition assay based on starch iodine method and in vitro anti-inflammatory were done by using inhibition of protein denaturation assay. Results: The pharmacognostical standards were also laid down for each sample. Morpho-anatomical characters had no distinct variation in all the collected samples of Eastern Ghats. The quantification of diosgenin (without hydrolysis of samples) in the collected germplasm varies significantly from 0.002 to $0.076 \%$ on dry weight basis. The maximum content was recorded in NBCS-06 from Patiya, Bhubaneswar and was identified as distinct chemotype with high metabolite content. $\mathrm{IC}_{50}$ value of Costus speciosus extract in starch-iodine assay was found to be maximum in NBCS- $6(87.54 \mu \mathrm{g} / \mathrm{ml})$ and inhibition of protein denaturation assay was found to be maximum in NBCS- $11(73.91 \mu \mathrm{g} / \mathrm{ml})$, respectively. Conclusion: The study suggests that the Costus speciosus germplasm possess potential anti-inflammatory and anti-diabetic activity and comparative pharmacognostical parameters will be useful in collection of location specific potential samples for industrial usage along with quality control of raw materials.

Key words: Costus speciosus, HPTLC, Diosgenin, Anti-inflammatory, Anti-diabetic.
\end{abstract}

\section{INTRODUCTION}

Costus speciosus (Koen.) Smith (family Costaceae), is a perennial rhizomatous herb commonly known as "Crepeginger". It is widely distributed in central parts of India, Sub-Himalayan tract, Karnataka, Western Ghats of Maharashtra and Kerala. ${ }^{2}$ The rhizome is useful to treat fever, cough, indigestion, asthma, helminthiasis, bronchitis and skin diseases. Diosgenin is the principle constituent of the rhizome used in the commercial production of steroidal hormones ${ }^{3}$ along with, tigogenin and saponin as other key ingredients. ${ }^{4}$

The anti-inflammatory and antipyretic properties were proved in the Rhizome and also possess significant hepatoprotective activity. ${ }^{5}$ C. speciosus leaf is used as a bath for patients with high fever. Rhizome juice is given traditionally with sugar to treat leprosy and for headache relief. ${ }^{6,7}$ Furthermore, its alkaloid extract is used as a muscle relaxant with an antispasmodic effect. ${ }^{8}$ C. speciosus is also used as a plant food in Southeast Asia. ${ }^{9}$

Aqueous extract of Rhizome is shown to possess antimicrobial activity. ${ }^{10}$ The leaves are also used to control diabetes. ${ }^{11}$

Ayurveda acclaimed variation in the quality due to impact of season, altitude, soil and period of harvesting on the content of active principles in the plants. Considering this fact, the study was aimed to evaluate the pharmacognostical parameters in C. speciosus germplasm collected from different locations of Eastern Ghats. The variability in diosgenin content was also recorded through HPTLC method. ${ }^{12}$ The present work may be helpful in the identification and quality control of raw material used in various Ayurvedic formulations.

\section{MATERIALS AND METHODS}

\section{Chemicals and reagents}

Solvents and chemicals viz. soluble starch, iodine, aluminum chloride, sodium carbonate, folin's reagent, methanol, ethyl acetate, n-Hexane and diethyl ether were procured from SD Fine Chemicals, Mumbai, India and HPTLC precoated silica gel $60 \mathrm{f}_{254}(20 \times 20 \mathrm{~cm})$ plates were procured from Merck, India. Marker compound diosgenin was purchased from ChromaDex Inc, USA for quantification studies. Bovine Serum Albumin (BSA flakes, $>99.8 \%$ ) were purchased from SigmaAldrich (St. Louis, MO, USA). All the chemicals and reagents used in study were of analytical grade purity.
Cite this article: Kumar M, Misra A, Srivastava A, Shukla PK, Tewari LM, Srivastava S. Comparative Pharmacognostical and Pharmacological Evaluation of Costus speciosus (Koen) J.E. Sm. Germplasm Collected from Eastern Ghats of India. Pharmacog J. 2020;12(1):150-6. 


\section{Plant material and extraction protocol}

Rhizomes were collected during the month of September from Eastern Ghats region covering Orissa (India). Eleven samples were collected from varied condition(s); specimens were authenticated and deposited in repository of CSIR-NBRI with individual voucher number. GPS information of the collected samples was recorded. The samples were washed with water, chopped, and shade dried. The dried tubers were coarsely powdered by passing through 40 mesh sieve (up to $500 \mathrm{~mm}$ ). The material was then macerated (cold method) with methanol $(25 \mathrm{ml})$ for $24 \mathrm{~h}$ at room temperature $\left(25^{\circ} \mathrm{C} \pm 2^{\circ} \mathrm{C}\right)$ for 3 consecutive days. Extraction was repeated thrice, filtered (Whatman no. 4), and the pooled filtrate was dried in a rotatory evaporator (Buchi, USA) under standard conditions of temperature $\left(55^{\circ} \mathrm{C} \pm 2^{\circ} \mathrm{C}\right)$ and pressure (40 mbar). The nature and yield (\%) of extract obtained in each germplasm was also documented.

\section{Morpho-anatomical studies}

The freshly collected samples were preserved in $70 \%$ ethanolic solution for macro-morphological studies. The anatomical studies were performed as per standard method. ${ }^{13}$ Free hand sectioning was done to obtain thin sections so that cellular details are clearly visible. Sections were stained with $0.1 \%$ toluidine blue 'O' solution for 30 second to visualize the secondary anatomical structures. The stained sections were mounted with glycerine on the glass slide and then observed under light microscope. Photomicrographs were taken with Nikon Advance Research Microscope, Eclipse 80i, Nikon instruments Inc., USA.

\section{Physicochemical studies}

Various physicochemical parameters viz. Extractive values by cold maceration method in different solvents (hexane, alcohol and water) and LOD (loss on drying) were estimated as per the protocol of Ayurvedic Pharmacopeia of India. ${ }^{14,15}$ In addition, sugar, $\operatorname{starch}^{16,} \operatorname{tannin}^{17}$, phenolics, flavonoids ${ }^{18}$ were also analyzed through spectrophotometric methods as per standard protocols.

\section{High performance thin layer chromatography}

\section{Sample preparation}

The coarsely powdered rhizome ( $2 \mathrm{gm})$ was macerated with methanol for $24 \mathrm{~h}$ at room temperature $\left(25 \pm 2^{\circ} \mathrm{C}\right)$. Extraction was repeated thrice, filtered and pooled filtrate was dried in rotatory evaporator (Buchi, USA) under standard conditions of temperature $\left(55 \pm 2^{\circ} \mathrm{C}\right)$ and pressure (40 mbar) and finally lyophilized (Labconco, USA) to dry residue. The extractive yield of collected sample was calculated (\%).

\section{Preparation of standard and sample solutions}

The stock solution of standard Diosgenin $(1.0 \mathrm{mg} / \mathrm{ml})$ and plant samples $(10 \mathrm{mg} / \mathrm{ml})$ were freshly prepared in methanol. A working solution of $0.1 \mathrm{mg} / \mathrm{ml}$ diosgenin were diluted from the stock in same solvent to obtain dilutions in the concentration, ranging from $0.1-0.9 \mu \mathrm{g} / \mathrm{ml}$. The solutions were filtered through a $0.45 \mu \mathrm{m}$ Millipore membrane filter (Pall, USA) before application. The working dilutions were prepared freshly on the day of analysis.

\section{HPTLC conditions}

High performance thin layer chromatography was used for separation of the components present in extract, both quantitatively as well qualitatively. For quantitative analysis $10 \mu \mathrm{l}$ sample solution $(10 \mathrm{mg} / \mathrm{ml})$ was applied using $100 \mu \mathrm{l}$ sample syringe (Hamilton, Switzerland) on pre-coated plates with silica gel $60 \mathrm{~F}_{254}$ of $0.2 \mathrm{~mm}$ thickness as $6 \mathrm{~mm}$ wide bands positioned $10 \mathrm{~mm}$ from the bottom and $15 \mathrm{~mm}$ from side of the plate, using CAMAG Linomat V automated TLC applicator with nitrogen flow providing a delivery speed of $150 \mathrm{nl} / \mathrm{s}$ from application syringe. HPTLC plate was developed in a CAMAG twin trough glass chamber pre-saturated with mobile phase. After development, the chromatogram was air-dried and then derivatized with anisaldehydesulphuric acid reagent. The marker compounds were quantified using a CAMAG TLC Scanner equipped with CAMAG vision CAT software at $440 \mathrm{~nm}$. The following scan conditions were applied: slit width, $4 \mathrm{~mm} \times$ $0.45 \mathrm{~mm}$ and absorption-reflection mode. ${ }^{19}$

\section{Pharmacological evaluation}

\section{Antidiabetic activity}

\section{Starch-iodine assay}

Starch-iodine test was carried out according to the standard method. ${ }^{20}$ Inhibition of enzyme activity was calculated as following:

Inhibition of enzyme activity $(\%)=[(\mathrm{C}-\mathrm{S}) / \mathrm{C}] \times 100$.

Where $\mathrm{S}$ is the absorbance of the sample and $\mathrm{C}$ is the absorbance of blank (no extract).

\section{Anti-inflammatory activity \\ Inhibition of protein denaturation method}

The reaction mixture $(0.5 \mathrm{ml})$ consisted of $0.45 \mathrm{ml}$ bovine serum albumin (5\% aqueous solution) and $0.05 \mathrm{ml}$ of plant extract at different concentration. The samples were incubated at $37^{\circ} \mathrm{C}$ for $30 \mathrm{~min}$. After cooling the samples, $2.5 \mathrm{ml}$ phosphate buffer saline ( $\mathrm{pH}$ 6.3) was added to each tube. Turbidity was measured spectrophotometrically at $660 \mathrm{~nm}$. In control, $0.05 \mathrm{ml}$ distilled water was used instead of extracts, whilst product control test lacked bovine serum albumin. The percentage inhibition of protein denaturation was calculated as per standard protocol, and the formula is given below. The control represents $100 \%$ protein denaturation. The results were compared with acetylsalicylic acid $(250 \mathrm{mcg} / \mathrm{ml})$-treated samples. ${ }^{21,22}$

Percentage of inhibition $=\left[\left(\mathrm{Abs}_{\text {sample }}-\mathrm{Abs}_{\text {control }}\right) /\left(\mathrm{Abs}_{\text {sample }}\right)\right] \times 100$

\section{RESULTS AND DISCUSSION}

\section{Microscopical description}

On anatomical studies of collected 11 samples (rhizome), some common features were observed as follows: (1) single layered epidermis followed by 4-6 layered periderm, (2) Below this, a multilayered cortex is present having parenchymatous cells, (3) it contains scattered vascular bundle which is divided in to three zones i.e., cortical vascular bundle, endodermal vascular bundle and stellar vascular bundle, (4) xylem vessels were clearly seen and are surrounded by phloem cells, (5) Bunch of starch grains of varying sizes are seen scattered all around the cortex and pith region, (6) starch grains are medium to large in size, compactly arranged but sometimes distinctly placed. The starch grains are light colored, cylindrical in shape and showing clear hilum with concentric striations (Figure 1). There is no diagnostic difference observed among the anatomical structure of collected samples.

\section{Physicochemical and phytochemical studies}

A comparative pharmacognostical studies of Costus speciosus samples (rhizome) revealed variability in hexane, alcohol and water-soluble extractive among the collected 11 samples from 1.3-3.6 \%, 1.33-5.3 $\%$ and $4.0-13.1 \%$ respectively. It is observed that within the samples, water soluble extractive was found to be maximum, followed by hexane and ethanol soluble extractives. These (extractive values) are primarily useful for determination of exhausted drug and was found to be within the limits of API. The LOD (\%) of collected samples ranges from 5.5 to $8.8 \%$, maximum and minimum content was observed in NBCS-10 and NBCS-9 (Figure 2). 


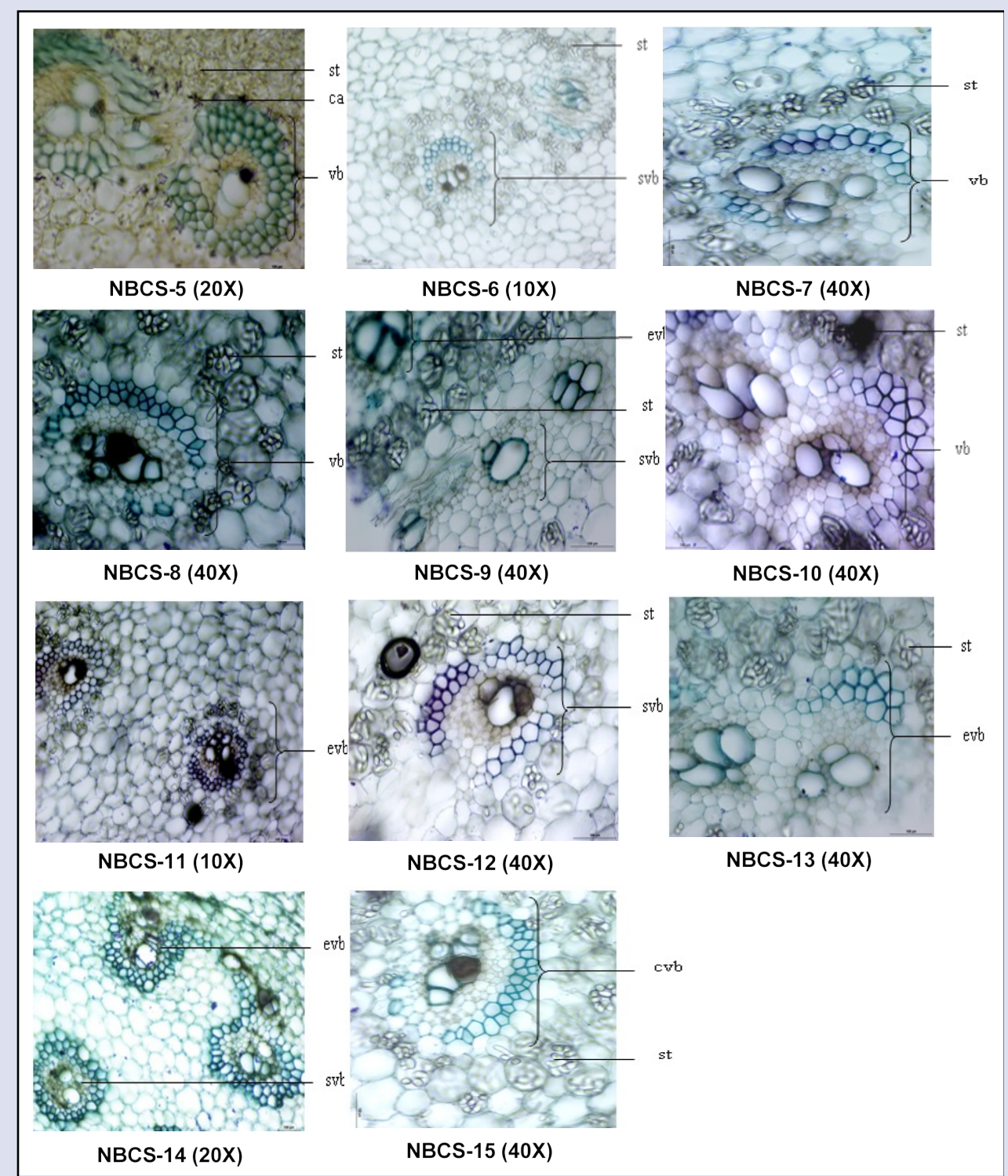

Figure 1: Microscopical description of Costus speciosus rhizome of the collected populations.

Abbreviations: vb - vascular bundles, ol - oil globule, st- starch granules, ca- calcium oxalate crystal, svbstellar vascular bundle, evb-endodermal vascular bundle, cvb- cortical vascular bundle.

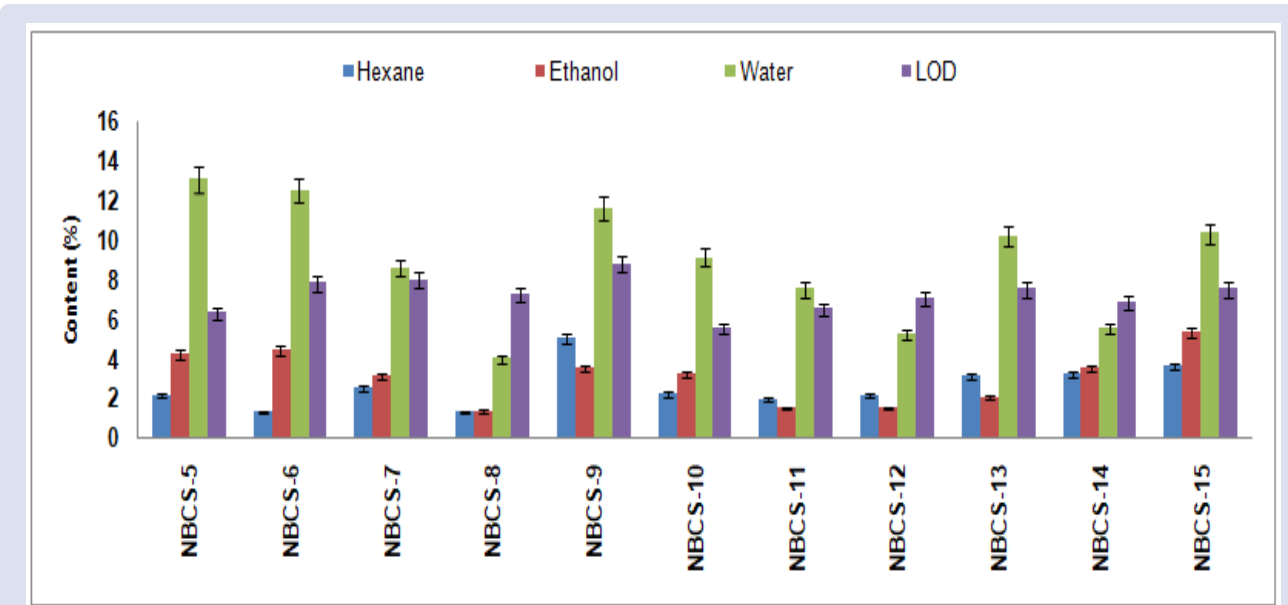

Figure 2: Physicochemical standards of Costus speciosus sample collected from Eastern Ghats. Values are mean \pm S.E. 
The phytochemical estimation of various metabolites in the rhizome viz. total sugar, total starch, total phenolic and flavonoid through spectrophotometer method varies from $0.2-0.54 \%, 0.38-0.6 \%, 0.036$ $-0.162 \%$ and $0.073-0.322 \%$ respectively (Figure 3 ). The starch content within each sample was found maximum than other metabolites, which is true in a sense that rhizome is vegetative part and serve as food storage unit of plant system.

\section{HPTLC quantification of marker compound}

The HPTLC study was done on the methanolic extract without hydrolysis with intent to provide a simple method for quality control. The extractive yield (methanolic) of Costus speciosus within the population significantly $(p<0.05)$ varies from 1.48 to $8.2 \%$. HPTLC condition(s), namely, selection of mobile phase, absorption maxima and slit dimensions was standardized to provide an accurate, precise, and reproducible method for the quantification of diosgenin. The method development was initiated with separation of diosgenin (extract) in various solvent systems by hit and trial method and finally a binary solvent system of $n$-Hexane: ethyl acetate $(7: 2 \mathrm{v} / \mathrm{v})$ was selected based on separation of unknown markers from diosgenin. The absorption spectrum of diosgenin was observed at $440 \mathrm{~nm}$ after scanning the entire UV range of $200-800 \mathrm{~nm}$. In sample, diosgenin was identified at $R_{f} 0.23$ \pm 0.05 . The saturation time for the development of chromatogram was optimized to $20 \mathrm{~min}$ for a good resolution of the diosgenin markers and the total run time was $30 \mathrm{~min}$ at room temperature $\left(27 \pm 2^{\circ} \mathrm{C}\right)$. Purity of the bands in the samples was confirmed by comparing band spectra of sample with the corresponding band spectra of standard at the start, middle and end position of the band peak.

The quantification of diosgenin without hydrolysis within the population revealed that the content varies from $0.002-0.076 \%$ on dry weight basis and the maximum content was recorded in NBCS - 06 from Patiya, Bubhneshwar. The minimum content was in NBCS-11 from Dubri, Jajpur (Table 1).

\section{Anti-diabetic activity}

In vitro anti-diabetic potential of Costus speciosus was assessed by starch-iodine colour assay. Data of starch-iodine show that activity increases linearly with increase in concentration, i.e. $20-100 \mu \mathrm{g} / \mathrm{ml}$, IC50 value of Costus speciosus extract was found maximum in NBCS- 6 $(87.54 \mu \mathrm{g} / \mathrm{ml})$ respectively (Figure 4$)$.

\section{Anti-inflammatory activity}

Protein denaturation is a process in which proteins lose their tertiary structure and secondary structure by application of external stress or compound. Denaturation of proteins is a well-documented cause of inflammation. As part of the investigation on the mechanism of the anti-inflammation activity, ability of plant extract to inhibit protein denaturation was studied. It was effective in inhibiting heat-induced albumin denaturation. Maximum inhibition i.e. $73.91 \mu \mathrm{g} / \mathrm{ml}$ was observed in NBCS-11 (Figure 5).

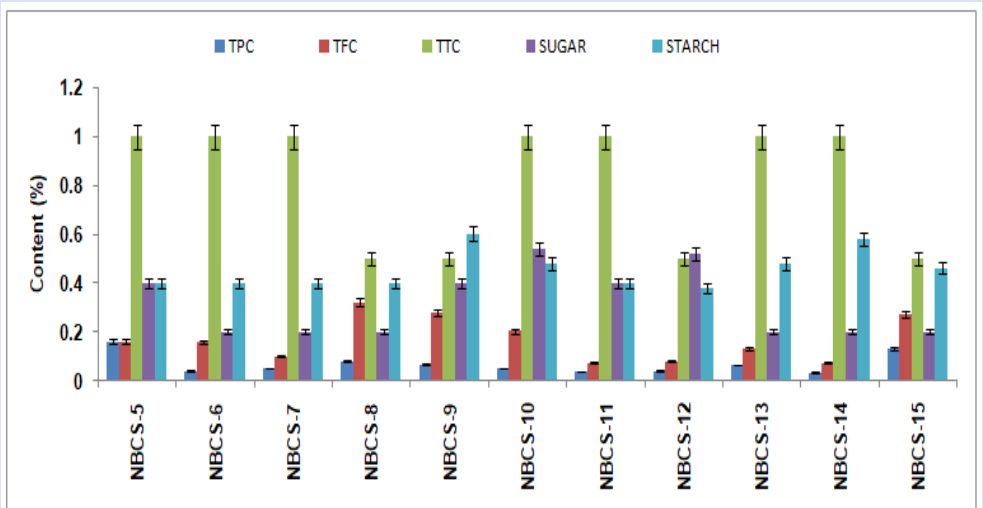

Figure 3: Phyto-chemical evaluations of Costus speciosus samples from Eastern Ghats. Values are mean \pm S.E.

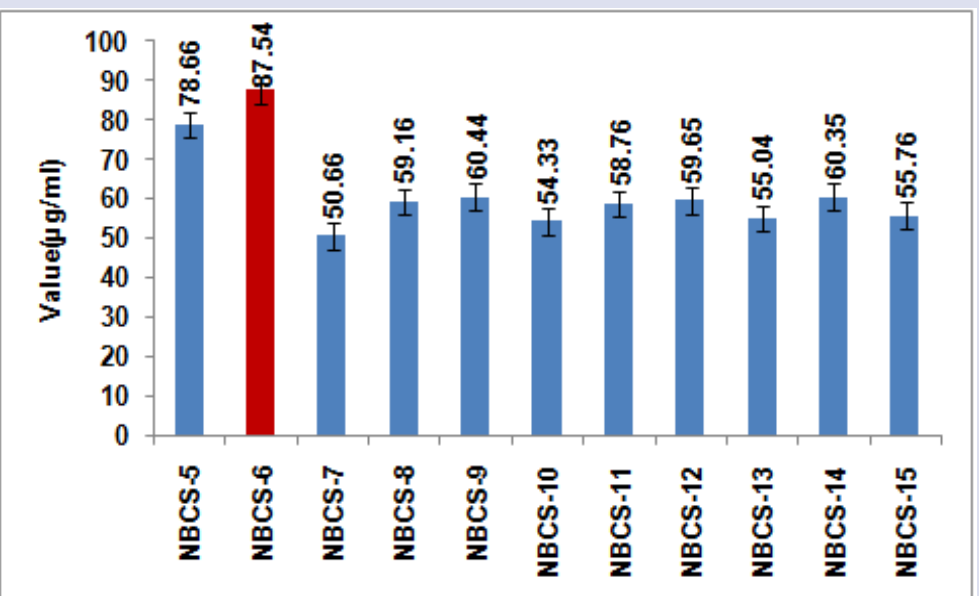

Figure 4: Anti-diabetic potential of Costus speciosus collected from Eastern Ghats. Values are mean \pm S.E. 


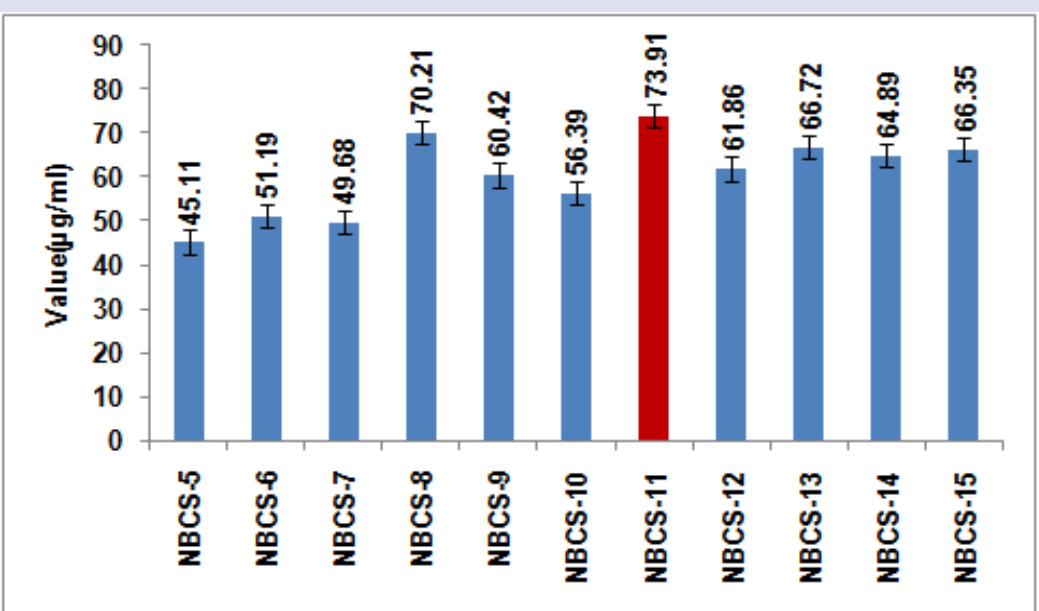

Figure 5: Anti-inflammatory potential of Costus speciosus collected from Eastern Ghat Values are mean \pm S.E.

Table 1: Quantification of diosgenin in 11 different populations of Costus speciosus.

\begin{tabular}{ccc}
\hline Sample code & Locations & Diosgenin content (\% dry wt. basis) \\
\hline NBCS -05 & Raigada & $0.038 \%$ \\
NBCS -06 & Patiya, Bhubaneswar & $0.076 \%$ \\
NBCS -07 & Kailashpurgati, Rayagada & $0.039 \%$ \\
NBCS -08 & Bhubaneswar & $0.048 \%$ \\
NBCS -09 & Madhopur & $0.046 \%$ \\
NBCS -10 & Anandapur & $0.007 \%$ \\
NBCS -11 & Duburi, Jajpur & $0.002 \%$ \\
NBCS -12 & Sambalpur & $0.017 \%$ \\
NBCS -13 & Sambhalpur university & $0.02 \%$ \\
NBCS -14 & Attabira, Bargada & $0.024 \%$ \\
NBCS -15 & Deogarh, Shambhalpur & $0.01 \%$ \\
\hline
\end{tabular}

\section{CONCLUSION}

This study will help in promoting the site specific collection of high metabolite yielding germplasm to meet out the industrial demand of good quality raw material. The develop method will aid in regulation of quality standard and also batch to batch consistency raw materials in industry.

\section{ACKNOWLEDGMENT}

The authors are thankful to the Director, CSIR-National Botanical Research Institute, Lucknow for providing necessary facilities during the course of the experiment. Authors are thankful to NASF, Indian Council of Agriculture Research, New Delhi, India for financial support.

\section{CONFLICTS OF INTEREST}

There is no conflicts of interest.

\section{REFERENCES}

1. Bhogaonkar PY, Devarkar VD, Lande SK, Physical characterization of Costus speciosus (Koenig Ex Retz.) smith a well known ayurvedic drug plant. Life Sciences Leflets. 2012;11:1-9.

2. Sabitha Rani A, Sulakshana G, Sudeshna Patnaik. Costus speciosus, an antidiabetic plant - Review. FS J Pharm Res. 2012;1(3).

3. Jha MK, Alam MB, Hossan MS, Islam A. In vitro antioxidant and cytotoxic potential of Costus speciosus (Koen) smith rhizome. International Journal of Pharmaceutical Sciences and Research. 2010;1(10):138-44.

4. Indu Sanadhya, Annika Durve, Meeta Bhot, Jossy Varghese, Naresh Chandra. Evaluation of medicinal activites of Costus speciosus. World Journal of Pharmaceutical Research. 2014;3(4):623-33.
5. Binny K, Sunilkumar G, Thomas D. Anti-inflammatory and antipyretic properties of the rhizome of Costus speciosus (Koen). SM. J Basic Clin Pharm. 2010;1:17781.

6. Khare CP. Indian Medicinal Plants. New York: Springer New York; 2007. Available from: http:// www.link.springer.com/10.1007/978-0-387-70638-2. [Last accessed on 2016 Nov 24]

7. Gupta RK. Medicinal and Aromatic Plants. New Delhi, India: CBS Publishers and Distributors; 2010.

8. Bhattacharya SK, Parikh AK, Debnath PK, Pandey VB, Neogy N. Pharmacological studies with the alkaloids of Costus speciosus (kemuka). J Res Indian Med. 1973;8:10-9

9. Swati S, Agarwal P, Kebuka (Costus Speciosus): A critical review. World J Pharm Pharm Sci. 2015;4:421-31.

10. Saraf A. Phytochemical and antimicrobial studies of medicinal plant Costus speciosus (koen). E J Chem. 2010;7:S405-13.

11. Benny M. Insulin plants in gardens. Nat Prod Rad. 2004;3:349-50.

12. Srivastava A, Kumar M, Misra A, Shukla PK, Agarwal PK, Srivastava S Evaluation of diosgenin content in Costus speciosus germplasm collected from Eastern Ghats of India and Identification of Elite Chemotypes Pharmacognosy Magazine. 2019.

13. Kokate CK. Practical pharmacognosy. Vallabh Prakashan, New Delhi. 2010;(4):17 26 .

14. Anonymous. WHO guidelines, Quality control methods for medicinal plant materials, A.I.T.B.S. publishers and distributors, New Delhi. 2002;6-84.

15. Indian pharmacopeia. Government of India, Ministry of health and Family welfare, New Delhi. 1996;(2):A-54.

16. The Ayurvedic Pharmacopoeia of India. Government of India, Ministry of Health and Family Welfare, New Delhi. 1989;(2):165:17-8.

17. Anonymous. Official Methods of Analysis of Association of official Analytical Chemists (AOAC), Virginia, US. 1984.

18. Bray HC, Thorpe WV. Analysis of phenolic compounds of interest in metabolism Methods of Biochemical Analysis. 1954;(1):27-52. 
19. International Conference on Harmonization (ICH), Text on Validation of Analytical Procedures, Harmonised Tripartite Guideline Prepared Within the International Conference on Harmonisation of Technical Requirements for the Registration of Pharmaceuticals for Human Use, ICH Q2A, Geneva. 1994.

20. Xiao Z, Storms R, Tsang A. A quantitative starch-iodine method for measuring alpha-amylase and glucoamylase activities. Anal Biochem. 2006:351:146-8.
21. Mizushima Y, Kobayashi M. Interaction of anti-inflammatory drugs with serum preoteins, especially with some biologically active proteins. J Pharm Pharmaco Res. 1968:20:169-73.

22. Sakat S, Juvekar AR, Gambhire MN. In vitro antioxidant and anti-inflammatory activity of methanol extract of Oxalis corniculata Linn. Ind J Phar Pharmacol Sci. 2010:2(1):146-55.

\section{GRAPHICAL ABSTRACT}

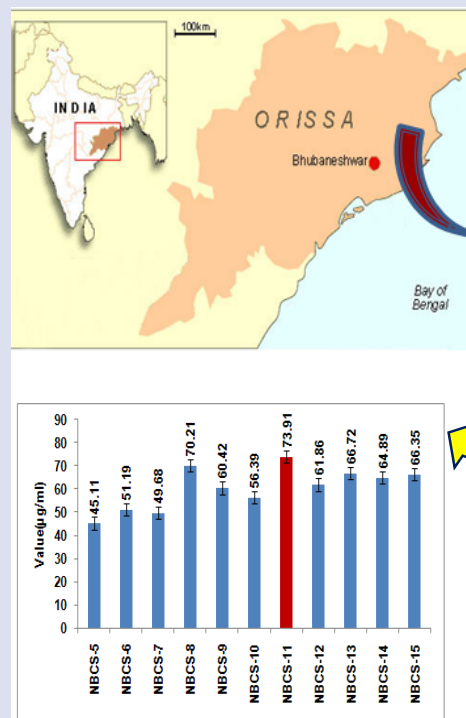

Anti-inflammatory $\underset{\substack{\text { Bayd of } \\ \text { Bengal }}}{ }$

(1)
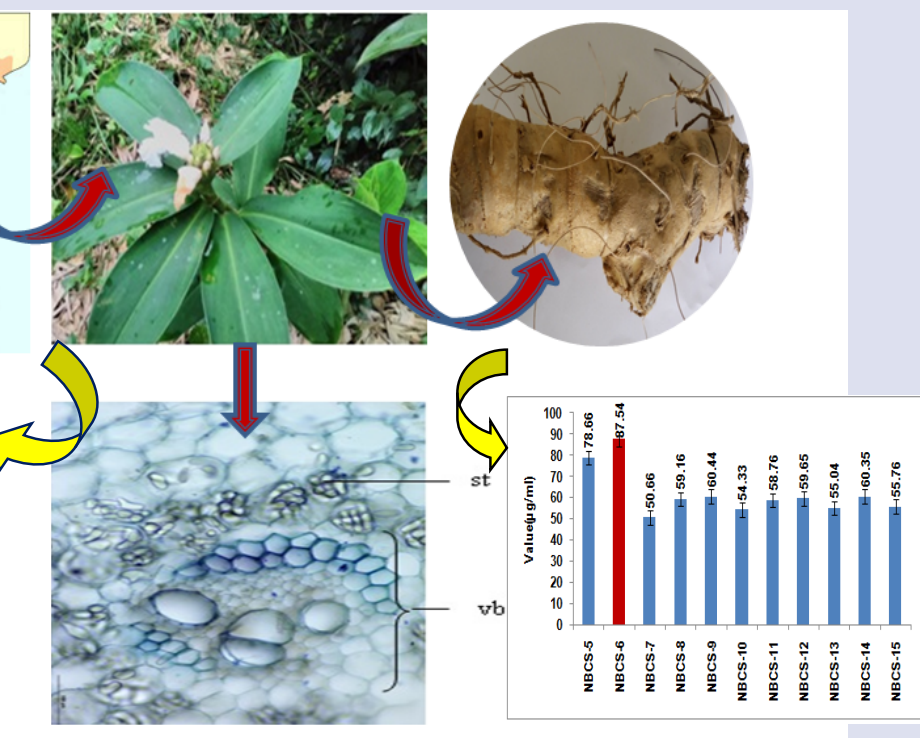

Anti-diabetic

\section{Graphical Representation of Costus speciosus}

\section{ABOUT AUTHORS}

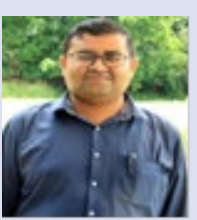

Mr. Manish Kumar: Senior Research Fellow (ICAR-SRF) in Pharmacognosy Division at CSIR-National Botanical Research Institute; Lucknow, INDIA. He is working in the area of analytical chemistry, anatomical study, molecular profiling and chemotaxonomy on medicinal plants. He has 9 publications in peer reviewed journals.

Email id: mnubhu@gmail.com

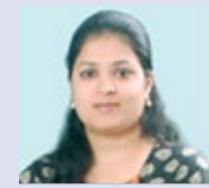

Dr. Ankita Misra: Young Scientist in Pharmacognosy Division at CSIR-National Botanical Research Institute; Lucknow, INDIA. She is working in the area of analytical chemistry on medicinal plants, chemotaxonomy, bioprospection and natural product development, handling major analytical instruments including HPLC, HPTLC, OPLC and column chromatography for quality control of herbal drugs. She has 32 publications in peer reviewed journals and 2 patented products are also to her credit.

Email id: anku.mis@gmail.com

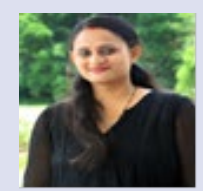

Mrs. Akanksha Srivastava: Senior Research Fellow (ICAR-SRF) in Pharmacognosy Division at CSIR-National Botanical Research Institute; Lucknow, INDIA. She is working in the area of in vitro pharmacological evaluation, and quality control of herbal drugs. She has 4 publications in peer reviewed journals. Email id: srivastavakn89@ gmail.com

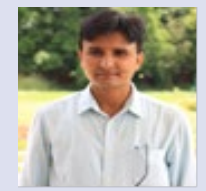

Dr. Pushpendra Kumar Shukla- Young Scientist in Pharmacognosy division, CSIR- National Botanical Research Institute, Lucknow. He is working in the area of analytical chemistry and chemotaxonomy, isolation of active metabolites and handling of sophisticated instruments like HPTLC, HPLC, OPLC, AAS, for identification and quantification of metabolites. He has 15 publications in peer reviewed journals Email id: itspushpendra85@gmail. com 
Dr. Sharad Srivastava: Senior Principal Scientist in Pharmacognosy Division at CSIR-National Botanical Research Institute; Lucknow, INDIA. He has made significant contributions to quality control of crude drugs/products, chemotaxonomy, bio-prospection and natural product development and have developed quality parameters of single crude drugs (more than 70 medicinal plants) and also identified biomarkers for their quality control. He has contributed 30 monographs of single herbal drugs in Ayurvedic Pharmacopoeia of India. He has 145 publications in peer reviewed journals, 17 patents and developed some technologies/formulations, few has already been transferred to industry. Email id: sharad_ks2003@yahoo.com

Cite this article: Kumar M, Misra A, Srivastava A, Shukla PK, Tewari LM, Srivastava S. Comparative Pharmacognostical and Pharmacological Evaluation of Costus speciosus (Koen) J.E. Sm. Germplasm Collected from Eastern Ghats of India. Pharmacog J. 2020;12(1):150-6. 